\title{
A nuclear shift of GSK3 $\beta$ protein is an independent prognostic factor in prostate cancer
}

\author{
Till Eichenauer ${ }^{1,2, *}$, Mohammad Hussein ${ }^{1, *}$, Claudia Hube-Magg ${ }^{1}$, Martina Kluth ${ }^{1}$, \\ Franziska Büscheck ${ }^{1}$, Doris Höflmayer ${ }^{1}$, Maria Christina Tsourlakis $^{1}$, Stefan \\ Steurer $^{1}$, Till S. Clauditz ${ }^{1}$, Andreas M. Luebke ${ }^{1}$, Eike Burandt ${ }^{1}$, Waldemar Wilczak ${ }^{1}$, \\ Andrea Hinsch'1, David Dum ${ }^{1}$, Burkhard Beyer ${ }^{3}$, Thomas Steuber ${ }^{3}$, Hartwig Huland ${ }^{3}$, \\ Markus Graefen ${ }^{3}$, Ronald Simon ${ }^{1}$, Guido Sauter ${ }^{1}$, Nathaniel Melling ${ }^{4}$, Thorsten \\ Schlomm ${ }^{5}$ and Sarah Minner ${ }^{1}$

\footnotetext{
${ }^{1}$ Institute of Pathology, University Medical Center Hamburg-Eppendorf, Hamburg, Germany

${ }^{2}$ Department of Urology, University Medical Center, Hamburg-Eppendorf, Hamburg, Germany

${ }^{3}$ Martini-Clinic, Prostate Cancer Center, University Medical Center Hamburg-Eppendorf, Hamburg, Germany

${ }^{4}$ Department of General, Visceral and Thoracic Surgery, University Medical Center Hamburg-Eppendorf, Hamburg, Germany

${ }^{5}$ Department of Urology, Charité-Universitätsmedizin Berlin, Berlin, Germany

*These authors contributed equally to this work
}

Correspondence to: Ronald Simon, email: R.Simon@uke.de

Keywords: GSK3beta; prostate cancer; prognosis; immunohistochemistry

Received: January 16, $2019 \quad$ Accepted: February 15, $2019 \quad$ Published: March 01, 2019

Copyright: Eichenauer et al. This is an open-access article distributed under the terms of the Creative Commons Attribution License 3.0 (CC BY 3.0), which permits unrestricted use, distribution, and reproduction in any medium, provided the original author and source are credited.

\section{ABSTRACT}

Glycogen synthase kinase $3 ß$ (GSK3ß) regulates many cancer relevant cellular processes and represents a potential therapeutic target. GSK3ß overexpression has been linked to adverse tumor features in many cancers, but its role in prostate cancer remains uncertain. We employed immunohistochemical GSK3ß expression analysis on a tissue microarray with 12,427 prostate cancers. Cytoplasmic and nuclear GSK3B staining was separately analyzed. GSK3ß staining was absent in normal prostate epithelium, whereas $57 \%$ of 9,164 interpretable cancers showed detectable GSK3B expression. Cytoplasmic staining was considered weak, moderate, and strong in $36 \%, 19.5 \%$ and $1.5 \%$ of tumors and was accompanied by nuclear GSK3ß staining in $47 \%$ of cases. Cytoplasmic GSK3ß staining as well as nuclear GSK3ß accumulation was associated with advanced tumor stage, high Gleason grade, presence of lymph node metastasis and early biochemical recurrence $(p<0.0001$ each for cytoplasmic staining and nu-clear accumulation). Prognosis of GSK3ß positive cancers became particularly poor if nuclear GSK3ß staining was also seen $(p<0.0001)$. The prognostic impact of nuclear GSK3ß accumu-lation was independent of established preoperative and postoperative parameters in multivari-ate analyses $(p<0.0001)$. The significant association of GSK3ß expression with deletions of PTEN, 3p13 ( $p<0.0001$ each), $5 q 21(p=0.0014)$ and $6 q 15(p=0.0026)$ suggest a role of GSK3B in the development of genomic instability. In summary, the results of our study identify GSK3B as an independent prognostic marker in prostate cancer. 


\section{INTRODUCTION}

Prostate cancer is the 2nd most prevalent cancer in men in Western societies [1], but only a small subset is highly aggressive and requires extensive treatment $[2,3]$. Presently Gleason grade, tumor extent on biopsies, prostate-specific antigen (PSA), and clinical stage are recognized prognostic parameters. These factors are statistically powerful, but not always sufficient for individual treatment decisions. Thus it is hoped that new biomarkers will enable a more reliable prediction of prostate cancer aggressiveness.

Glycogen synthase kinase $3 \beta$ (GSK3ß) is a ubiquitously expressed multifunctional serine/threonine kinase that was originally named after its function as an enzyme in glycogen biosynthesis. It also plays a key role in regulating a multitude of other pathways affecting metabolism, proliferation, survival and cell motility [4]. GSK3ß shuttles between the cytoplasm and the nucleus where it is believed to exert distinct functions [5]. Deregulation of GSK3ß has been implicated in the development of many human diseases, including diabetes, cardiovascular diseases, Alzheimer's, Parkinson's, and cancer [4]. Overexpression of GSK3ß has been linked to adverse tumor phenotype and poor prognosis in several cancer types, including breast [6,7], ovarian [8], oral cavity [9], urinary bladder [10], non-small cell lung [11], gastric [12], and pancreatic cancers [13]. Based on these findings, GSK $3 ß$ has gained considerable interest as a target for novel therapies. At present, more than 50 GSK3ß inhibitors have been described [4] and clinical phase 1/2 trails have been initiated in pancreatic cancer (NCT01632306) and leukemia (NCT01214603). Accumulating evidence suggests that GSK3ß may also be clinically relevant in prostate cancer [14, 15]. Here, GSK3 3 is known to be involved in the regulation of androgen receptor (AR) stability, localization, and androgen-stimulated gene expression [16-22]. Two studies analyzing GSK3ß expression on clinical samples from 79 and 499 prostate cancer patients suggested associations between GSK3ß overexpression and high Gleason score [22] and potentially also poor patient prognosis [15].

To study the impact of GSK3ß expression on prostate cancer phenotype and patient prognosis, we analyzed cytoplasmic and nuclear GSK3ß expression in more than 12,400 prostate cancer specimens using a preexisting tissue microarray (TMA).

\section{RESULTS}

\section{Technical issues}

A total of 9,164 of 12,427 tumor samples (74\%) were interpretable in our TMA analysis. Reasons for noninformative cases $(n=3,263 ; 26 \%)$ included lack of tissue samples or absence of unequivocal cancer tissue in the TMA spot.

\section{GSK3ß expression in normal and cancerous prostate tissues}

Normal prostate tissue was negative for GSK3ß. In cancers, GSK3ß staining was localized in the cytoplasm and/or in the nucleus. Representative images of cytoplasmic and nuclear GSK3ß staining are given in Figure 1. Cytoplasmic staining (irrespective of nuclear staining) was seen in 5,223 of our 9,164 (57\%) interpretable prostate cancers and was considered weak in $36 \%$, moderate in $19.5 \%$ and strong in $1.5 \%$ of cases. Cytoplasmic and nuclear staining was tightly linked: Cytoplasmic staining was accompanied by nuclear staining in 2,465 (47\%) of 5,223 cases and the likelihood for nuclear tumor cell staining rose with increasing levels of cytoplasmic staining (Figure 2; $p<0.0001$ ). Nuclear staining without cytoplasmic staining was seen in only 95 cases (1\%). To better understand the individual impact of cytoplasmic and nuclear staining, we re-grouped all cancers for the subsequent analyses according to the following criteria: no staining at all (negative, $n=3,846$ ), cytoplasmic staining without nuclear co-staining (cytoplasmic only, $n=2,758$ ), and cytoplasmic staining with nuclear co-staining (nuclear accumulation, $n=$ 2,560 , including the 95 cancers with isolated nuclear staining).

\section{Association with androgen receptor (AR)}

As GSK3 3 is an AR regulated gene, we compared data on AR expression from a previous study [23] with GSK3 3 expression patterns. IHC data on both GSK3ß and AR were available from 6,253 cancers. As expected, there was a strong positive association between AR expression and presence of both cytoplasmic and nuclear GSK3ß protein $(p<0.0001$ each; Figure 3$)$. Also nuclear GSK3 $\beta$ and nuclear AR expression correlated as well (Supplementary Figure 1).

\section{Association with TMPRSS2:ERG fusion status and ERG protein expression}

Data on TMPRSS2:ERG fusion status obtained by FISH were available from 5,556 and by IHC from 8,171 tumors with evaluable GSK3ß staining. Data on both ERG FISH and IHC were available from 5,365 of these cancers, and an identical result (ERG IHC positive and break by FISH or ERG IHC negative and missing break by FISH) was found in 5,137 of 5,365 (95.8\%) cancers. Both cytoplasmic expression and nuclear accumulation GSK3ß were strongly linked to TMPRSS2:ERG rearrangement and ERG expression $(p<0,0001$ each, Figure 4). For example, GSK3ß staining was seen in $44.5 \%$ of ERG-IHC negative but in $78.3 \%$ of ERG-IHC positive cancers. 
A
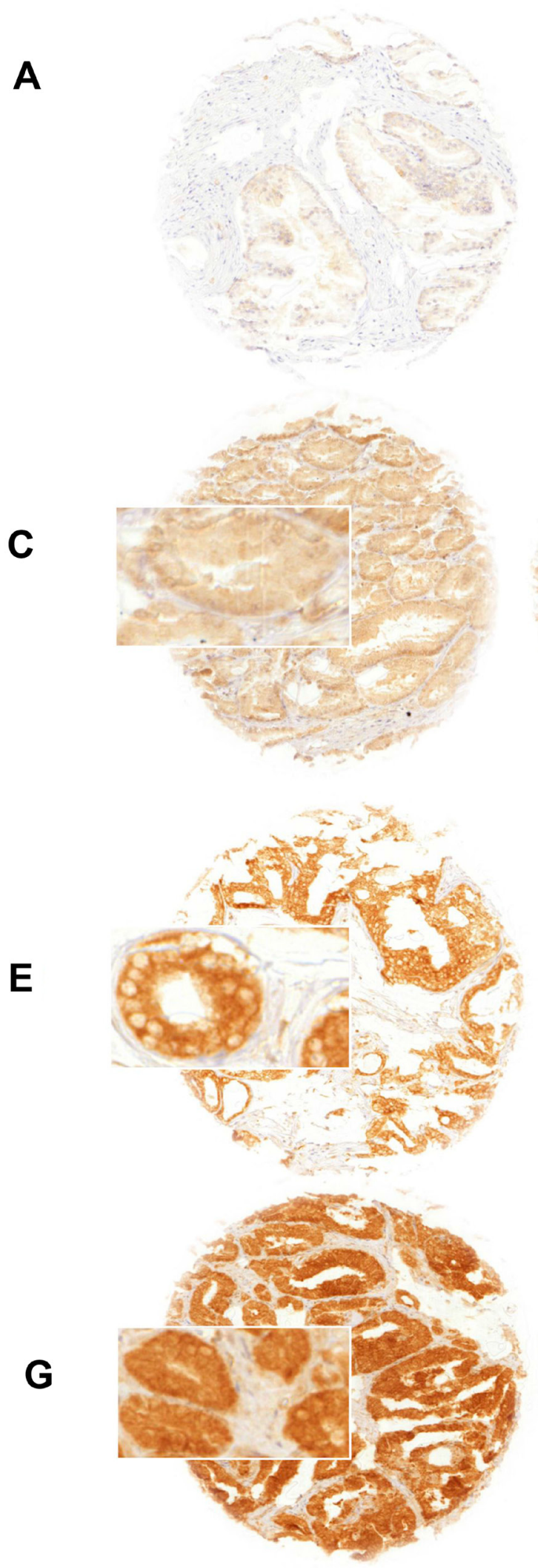

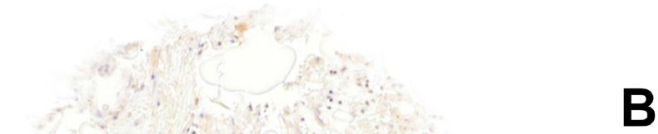
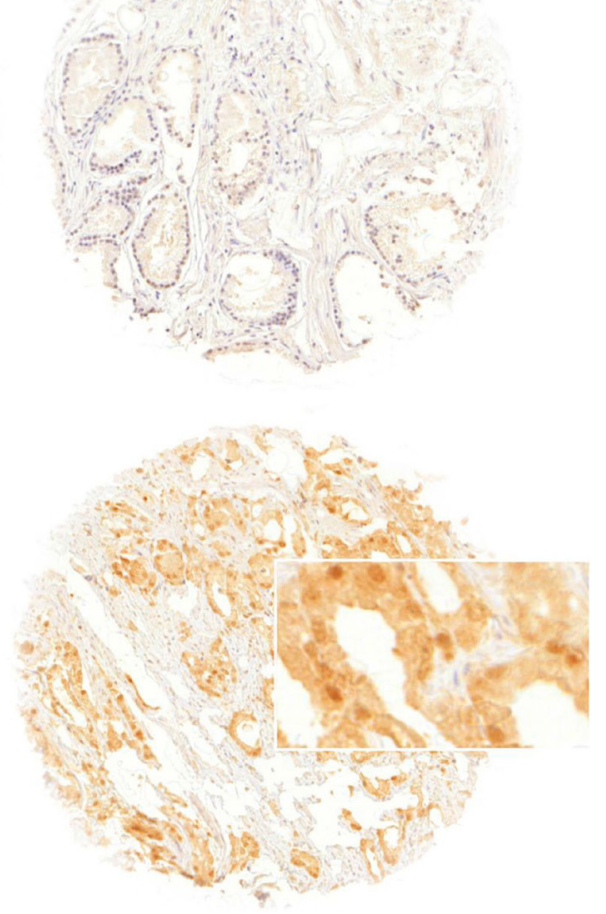

D

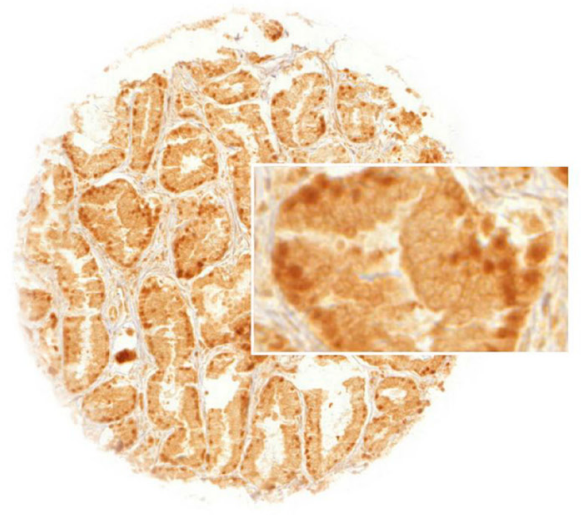

F

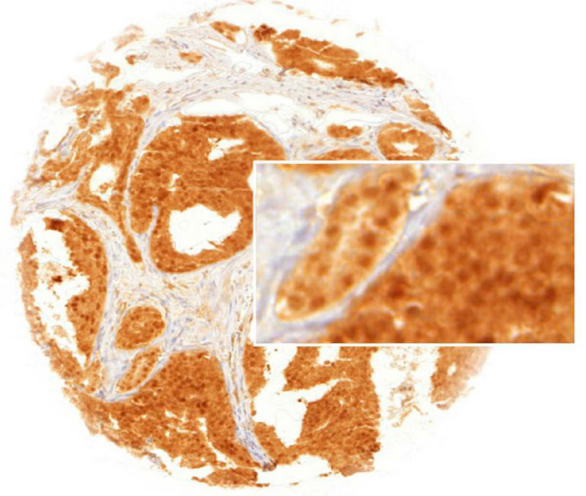

Figure 1: GSK3ß staining of (A) negative normal prostate tissue, (B) negative prostate cancer, (C) weak cytoplasmic only (D) weak cytoplasmic and nuclear accumulation, (E) moderate cytoplasmic only (F) moderate cytoplasmic and nuclear accumulation, (G) strong cytoplasmic only and $(\mathbf{H})$ strong cytoplasmic and nuclear accumulation. Spot size is $0.6 \mathrm{~mm}$ at $100 \times$ (inset $400 \times$ ) magnification. Nuclear accumulation denotes nuclear staining with/without cytoplasmic staining. 


\section{Associations with tumor phenotype}

Both the intensity of cytoplasmic GSK3ß staining and the presence of nuclear GSK3ß accumulation showed significant associations with adverse tumor features. This was particularly true for nuclear GSK3ß accumulation, which was associated with advanced tumor stage $(p<0.0001)$, high Gleason grade $(p<0.0001)$, lymph node metastasis $(p<0.0001)$, positive surgical margin $(p<0.0001)$ and high preoperative PSA level $(p=0.0002$, Table 1). Cytoplasmic GSK3ß expression levels showed comparable but somewhat weaker associations (Table 1). All these associations held true in the subset of ERG negative and ERG positive cancers (Supplementary Tables 1 and 2).

\section{Association to other key genomic deletions}

Comparison of GSK3ß expression with several of the most frequent genomic deletions in prostate cancer (PTEN, 3p13, 6q15 and 5q21) revealed that GSK3ß staining was strikingly linked to PTEN deletions $(p<0,0001$, Figure 5). Weaker associations were also found with deletions of $6 \mathrm{q} 15$ ( $p=0.0026), 5 \mathrm{q} 21$ ( $p=$ $0.0014)$ and $3 p 13(p<0.0001)$. However, subset analysis of ERG positive and ERG negative cancers revealed that the associations, with the exception of PTEN, were solely driven by ERG negative cancers ( $p \leq 0.002$ each).

\section{Association to tumor cell proliferation (Ki67LI)}

Presence of GSK3ß staining was significantly linked to increased cell proliferation as measured by Ki67LI. This held true for purely cytoplasmatic but all the more for combined cytoplasmatic and nuclear staining (nuclear accumulation) ( $p<0.0001$; Table 2). These associations were independent from the Gleason grade as they also held true in subgroups of tumors with identical Gleason score $(\leq 3+3,3+4,4+3 p<0.0001$ each and $\geq 4+4 ; p=0.0101)$.

\section{Association with PSA recurrence}

Follow-up data were available from 8,598 patients with interpretable GSK3ß staining on the TMA. The intensity of cytoplasmic GSK3ß staining was strongly linked to early biochemical recurrence $(p=0.0001$, Figure $6 \mathrm{~A})$. Factoring in the staining localization revealed that the prognosis of GSK3ß positive cancers deteriorated if the protein accumulated in the nucleus $(p<0.0001$, Figure $6 \mathrm{~B}$ ). These findings were independent of the ERG

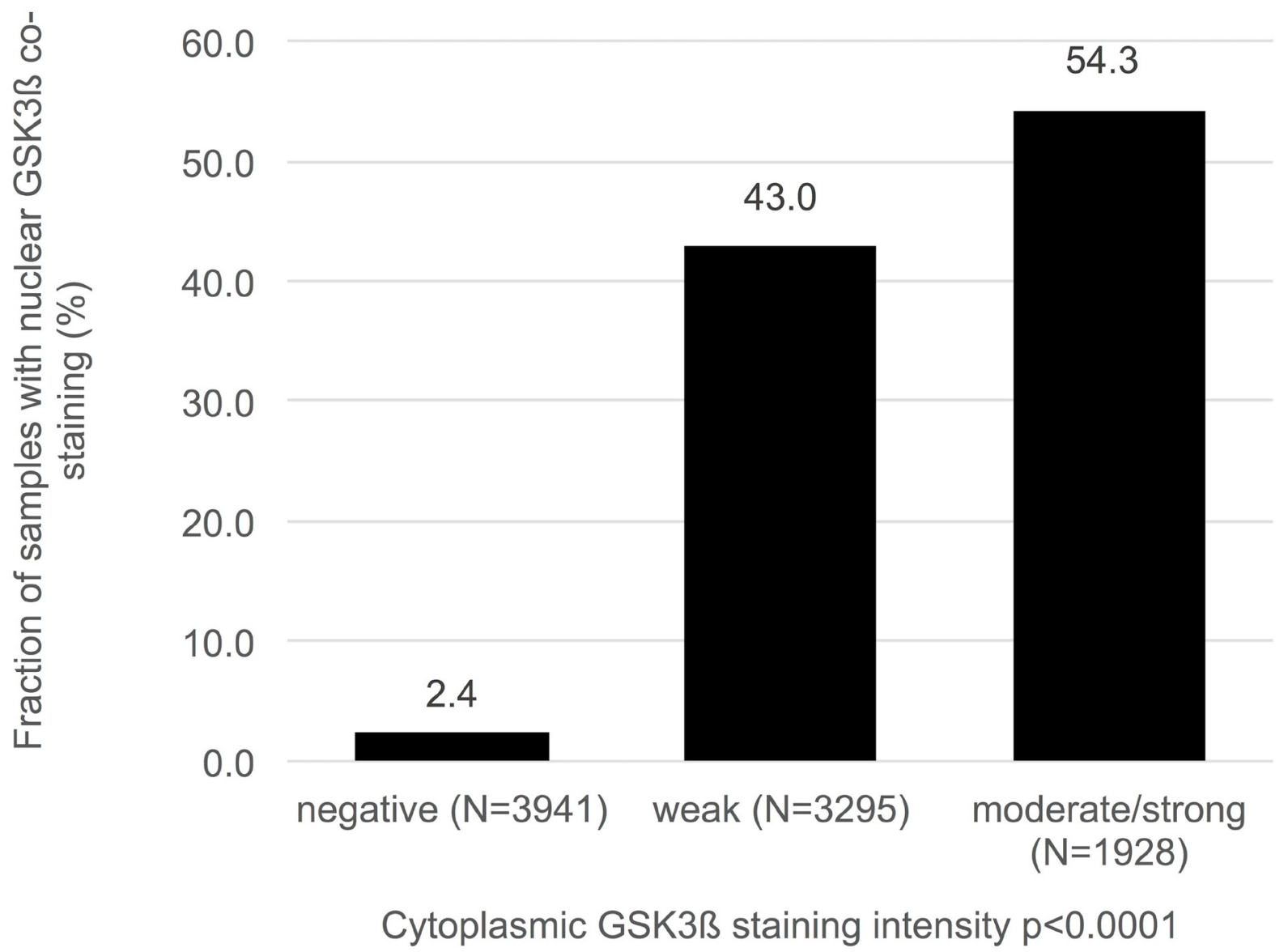

Figure 2: Association between cytoplasmic and nuclear GSK3ß staining. 
status (Figure 6B, 6C and 6E, 6F). To better understand the prognostic impact of nuclear GSK $3 ß$ accumulation, we performed subset analyses in tumors with comparable classical and quantitative Gleason grades. These analyses revealed that nuclear GSK3ß expression measurement did provide additional prognostic impact in morphologically well-characterized tumors with Gleason $3+4(p<0.0001)$ and Gleason $4+3$ ( $p=0.0002$, Figure 7A). Expansion of the subgroup analysis to the quantitative Gleason grade showed that nuclear GSK3ß accumulation even had a prognostic impact in several subsets of tumors with comparable fractions of Gleason 4 (Figure 7B-7H).

\section{Multivariate analysis}

Four different models of multivariate analyses were evaluated (Table 3, Supplementary Table 3). Scenario 1 evaluated the postoperatively available parameters (pathological tumor stage, pathological lymph node status $(\mathrm{pN})$, surgical margin status, preoperative PSA value and pathological Gleason grade obtained after the evaluation of the entire resected prostate and nuclear GSK3ß expression). In scenario $2 \mathrm{pN}$ was excluded. This approach can markedly increase case numbers and power of the test. Two additional scenarios 3 and 4 model the preoperative situation as much as possible. Since postoperative determination of a tumor's Gleason grade is "better" than the preoperatively determined Gleason grade (subjected to sampling errors and consequently undergrading in more than one third of cases [24]), scenario 3 included the postoperative Gleason grade instead of the Gleason grade originally obtained at biopsy in scenario 4. Nuclear GSK3ß accumulation provided highly significant prognostic value beyond the established preand postoperative parameters in all scenarios irrespective of the ERG status ( $p<0.0001$ for all scenarios). The univariate hazard ratio of nuclear GSK3ß accumulation for PSA recurrence-free survival was a moderate 2.06 (95\% CI 1.86-2.29, $p \leq 0.0001)$. The multivariate hazard ratio varied from 1.72 to 1.37 depending on the model used (Supplementary Table 3).

\section{DISCUSSION}

The results of our study demonstrate that nuclear GSK3ß protein accumulation is a moderate and independent predictor of poor prognosis in prostate cancer.

Cytoplasmic GSK3ß staining - with or without additional nuclear staining - was seen in $57 \%$ of 9,164 interpretable prostate cancers, while normal prostatic epithelial tissue was negative under the selected experimental conditions. Our results fit well to earlier work. Li et al. described higher cytoplasmic GSK3ß expression in 499 cancers as compared to 491 normal prostate samples using a customized IHC score [15]. Darrington et al. found cytoplasmic and nuclear GSK3ß

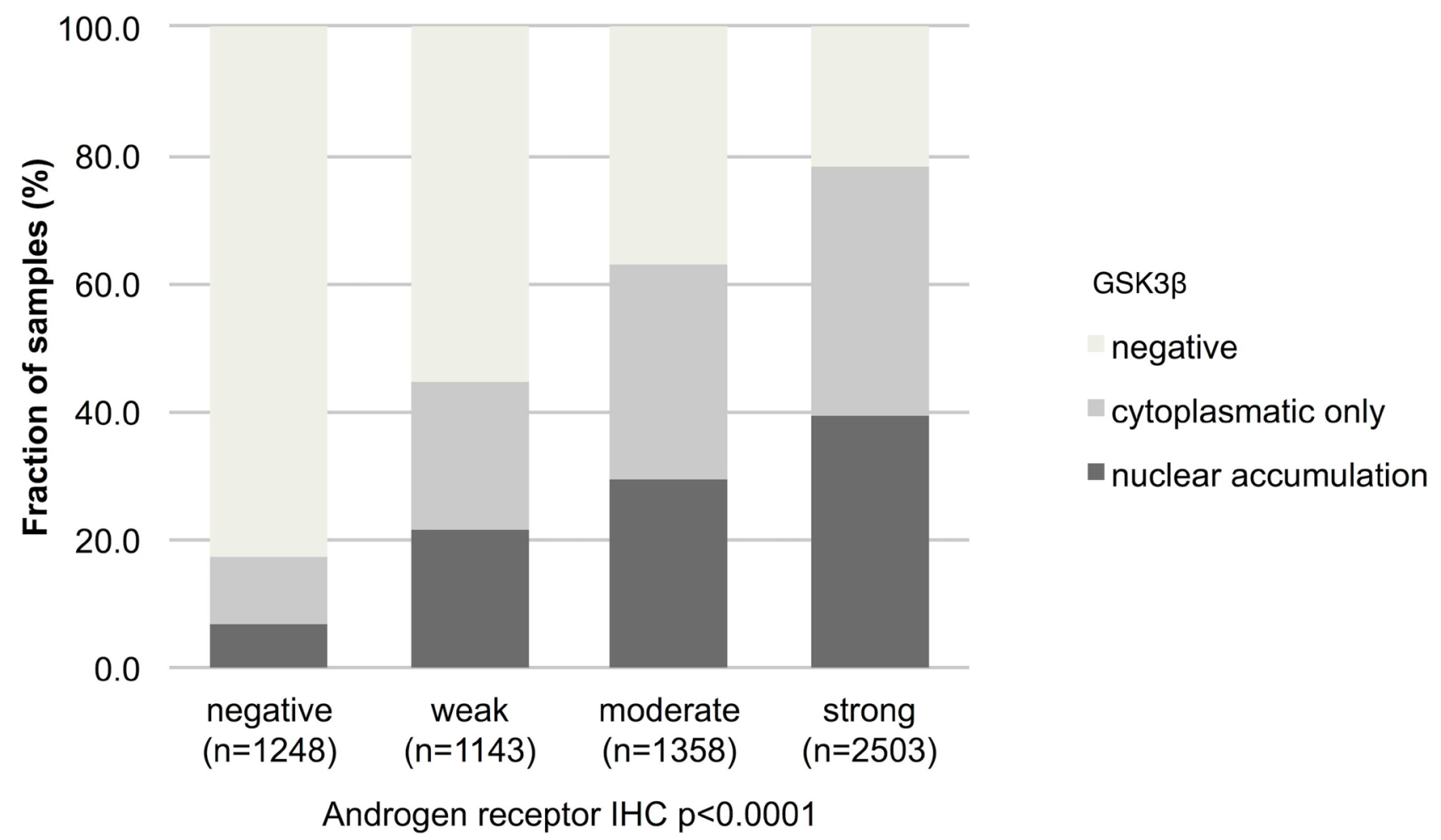

Figure 3: Association between GSK3ß staining pattern and expression of androgen receptor. Nuclear accumulation denotes nuclear staining with/without cytoplasmic staining. 
expression in $30 \%$ of 79 cancers but no GSK3ß staining in normal prostate epithelium [22]. The somewhat lower rate of GSK3ß positivity in the latter study as compared to our analysis has most likely technical reasons, including different antibodies (our study: Cell Signaling Technology \#12456 1:900; Darrington et al.: New England Biolabs \#27C10 1:20) and different IHC protocols (our study: autoclave pretreatment in pH7.8 TRIS-EDTA buffer, Darrington et al.: microwave pretreatment in $\mathrm{pH} 6$ citrate buffer). Others and we have demonstrated earlier that protocol modifications can dramatically impact the fraction of positive tissues in IHC experiments [25-28].

The most important finding of our study was a massive link between prostate cancer aggressiveness and translocation of the GSK3ß protein from the cytoplasm to the nucleus. In particular, nuclear GSK3ß accumulation was associated with adverse tumor features, including advanced pathological tumor stage, high Gleason grade, lymph node metastasis, elevated tumor cell proliferation and early PSA recurrence. It was not surprising to find the same associations (although weaker) for cytoplasmic staining, since nuclear accumulation was generally paralleled by a higher level of cytoplasmic GSK $3 ß$ staining. It is, thus, in line with our results that earlier studies focusing on cytoplasmic staining reported comparable associations with high Gleason score [22], advanced clinical stage, lymph node metastasis, extracapsular extension, high Gleason score and an increased risk of biochemical recurrence [15]. However, the particular strong prognostic impact of nuclear staining suggests, that tumor relevant functions of GSK3ß exist which are specifically linked to its nuclear localization. This is supported by earlier work on the nuclear functions of GSK3ß. Several studies showed that GSK3ß forms complexes with various cancer-relevant proteins specifically in the nucleus, including cyclin D1 [29], STAT [30], GATA-4 [31], c-myc [32], NRF2 [33], Snail [34] and p53 [35]. Schütz et al [17] showed that inhibition of GSK3ß induces nuclear export of the AR in prostate cancer cells. Thus nuclear GSK3ß increases nuclear AR even in the absence of androgens supporting the growth of prostate cancer cells. Accordingly, data are accumulating which suggest a general role of nuclear GSK3ß accumulation for cancer aggressiveness. For example, a shift from cytoplasmic to nuclear expression also paralleled progression of pancreatic cancer [13]. Studies describing a relationship between GSK3ß overexpression and poor patient outcome in breast $[6,7]$,

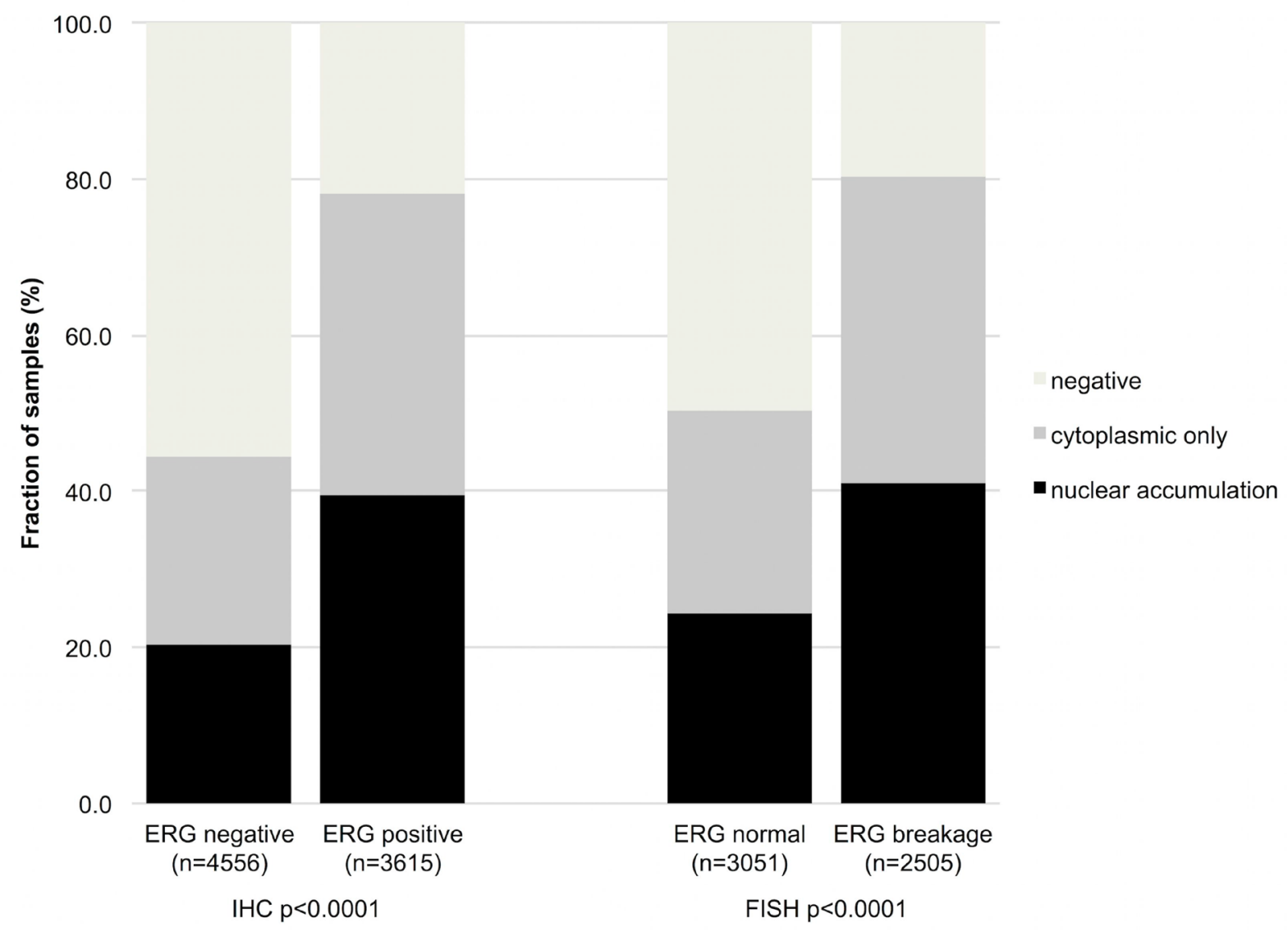

Figure 4: Association between increasing GSK3ß staining and ERG status determined by IHC and FISH. Breakage indicates rearrangement of the $E R G$ gene by FISH. 
Table 1: Association between cytoplasmic and nuclear GSK3ß immunostaining and prostate cancer phenotype

\begin{tabular}{|c|c|c|c|c|c|c|c|c|c|}
\hline \multirow[b]{2}{*}{ Parameter } & \multirow[b]{2}{*}{$N$} & \multicolumn{4}{|c|}{ Cytoplasmic GSK3ß (\%) } & \multirow[b]{2}{*}{$\boldsymbol{P}$} & \multicolumn{3}{|c|}{ Cytoplasmic and nuclear GSK3ß (\%) } \\
\hline & & Negative & Weak & Moderate & Strong & & $\begin{array}{c}\text { Cytoplasmic } \\
\text { only }\end{array}$ & $\begin{array}{c}\text { Nuclear } \\
\text { accumulation }\end{array}$ & $\boldsymbol{P}$ \\
\hline All cancers & 9,164 & 43.0 & 36.0 & 19.5 & 1.5 & & 29.6 & 27.4 & \\
\hline \multicolumn{10}{|l|}{ Tumor stage } \\
\hline pT2 & 5,596 & 46.8 & 35.1 & 16.9 & 1.2 & \multirow{3}{*}{$<0.0001$} & 30.4 & 22.8 & \multirow{3}{*}{$<0.0001$} \\
\hline pT3a & 2,121 & 36.7 & 37.9 & 23.4 & 2.0 & & 29.0 & 34.3 & \\
\hline pT3b-pT4 & 1,140 & 34.9 & 36.9 & 25.8 & 2.5 & & 25.4 & 39.7 & \\
\hline \multicolumn{10}{|c|}{ Gleason grade } \\
\hline$\leq 3+3$ & 1,922 & 58.3 & 32.8 & 8.8 & 0.2 & \multirow{6}{*}{$<0.0001$} & 27.7 & 14.0 & \multirow{6}{*}{$<0.0001$} \\
\hline $3+4$ & 5,030 & 41.9 & 36.7 & 19.9 & 1.6 & & 32.1 & 26.0 & \\
\hline $3+4$ Tert. 5 & 337 & 38.3 & 39.8 & 20.2 & 1.8 & & 27.7 & 34.0 & \\
\hline $4+3$ & 903 & 30.8 & 40.1 & 26.0 & 3.1 & & 30.1 & 39.1 & \\
\hline $4+3$ Tert. 5 & 500 & 29.4 & 33.0 & 34.8 & 2.8 & & 22.5 & 48.1 & \\
\hline$\geq 4+4$ & 466 & 34.6 & 33.3 & 29.6 & 2.6 & & 21.3 & 44.1 & \\
\hline \multicolumn{10}{|l|}{$\begin{array}{l}\text { Lymph node } \\
\text { metastasis }\end{array}$} \\
\hline N0 & 5,250 & 40.1 & 36.9 & 21.0 & 2.0 & \multirow{2}{*}{$<0.0001$} & 29.6 & 30.3 & \multirow{2}{*}{$<0.0001$} \\
\hline $\mathrm{N}+$ & 524 & 32.8 & 34.7 & 30.0 & 2.5 & & 24.2 & 43.0 & \\
\hline \multicolumn{10}{|c|}{$\begin{array}{l}\text { Preoperative } \\
\text { PSA level (ng/ml) }\end{array}$} \\
\hline$<4$ & 1,319 & 41.8 & 37.9 & 18.7 & 1.6 & \multirow{4}{*}{0.0731} & 33.1 & 25.2 & \multirow{4}{*}{$<0.000$} \\
\hline $4-10$ & 5,319 & 42.4 & 36.2 & 19.8 & 1.7 & & 30.1 & 27.5 & \\
\hline $10-20$ & 1,827 & 45.1 & 34.7 & 19.2 & 1.0 & & 27.1 & 27.8 & \\
\hline$>20$ & 653 & 45.2 & 33.4 & 19.9 & 1.5 & & 21.2 & 33.7 & \\
\hline \multicolumn{10}{|c|}{ Surgical margin } \\
\hline Negative & 7,253 & 43.8 & 36.3 & 18.4 & 1.5 & \multirow{2}{*}{$<0.0001$} & 30.1 & 26.1 & \multirow{2}{*}{$<0.0001$} \\
\hline Positive & 1,802 & 40.3 & 34.4 & 23.4 & 1.9 & & 27.0 & 32.7 & \\
\hline
\end{tabular}

Nuclear accumulation: nuclear staining with or without cytoplasmic co-staining.

ovarian [8], oral cavity [9], urinary bladder [10], lung [11] and gastric cancer [12] also regularly found nuclear GSK3 localization to be decisive for prognosis.

To learn more about the molecular events associated to GSK3ß up-regulation in prostate cancer, we made use of the molecular database attached to our TMA. The TMPRSS2:ERG gene fusion occurs in $40-60 \%$ of prostate cancers, and results in deregulation of more than 1,600 genes [23, 36, 37]. Activation of Wnt signaling belongs to the best-known consequences of $E R G$ fusion [36, 38, 39]. Wnt signaling stabilizes the transcription co-factor $ß$-catenin in the cytoplasm and triggers its translocation into the cell nucleus [40]. That GSK3ß controls Wnt signaling by inactivation of $\beta$-catenin both in the cytoplasm $[41,42]$ and in the nucleus [43] might, thus, explain the predominance of nuclear GSK $3 \beta$ in ERG positive cancers in our study. This assumption is further supported by earlier work showing that GSK3ß is up-regulated and translocated to the nucleus in response to activation of Wnt signaling $[44,45]$. Other genes of interest with respect to GSK3ß include the $A R$ and the PTEN tumor suppressor. The strong association between GSK3ß up-regulation and AR expression as well as PTEN loss in our study is in line with earlier work. For example, Mulholland et al. suggested a promiscuous growth signaling network governed by PTEN, AR, and GSK3ß, in which GSK3ß and PTEN loss cooperate for the progression to androgenindependent prostate cancer [19]. In this network, PTEN/GSK3ß signaling is believed to be at least partly functionally interchangeable with Wnt/ß-catenin signaling [19]. Moreover, GSK3ß has been shown to stabilize the AR protein and to enhance AR dependent transcription in some studies [46, 47], which fits well to the almost linear association between AR expression and both cytoplasmic and nuclear levels of GSK3ß in our study.

Besides deletions of PTEN, loss of certain small and large chromosomal regions is another hallmark of prostate cancer. Data from next generation sequencing studies 
- nuclear accumulation cytoplasmic negative
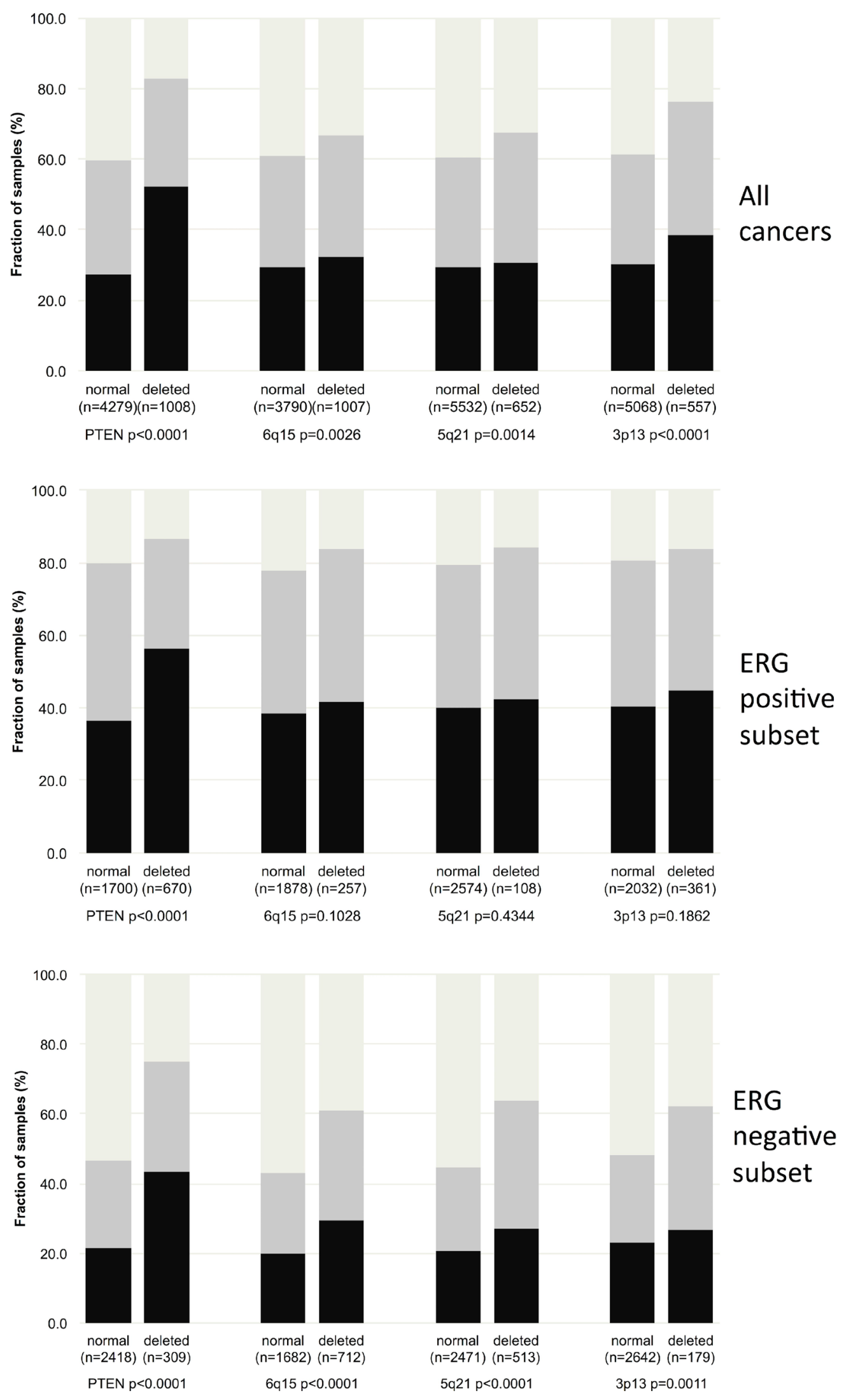

Figure 5: Association between GSK3ß localization and 10q23 (PTEN), 5q21 (CHD1), 6q15 (MAP3K7), 3p13 (FOXP1) deletion in all cancers, the ERG positive and the ERG negative subset. 
Table 2: Association between GSK3ß staining and Ki67 labeling index in all cancers and Gleason categories

\begin{tabular}{|c|c|c|c|c|c|}
\hline \multirow[t]{2}{*}{ Gleason } & \multirow{2}{*}{$\begin{array}{l}\text { GSK3ß } \\
\text { Negative }\end{array}$} & \multirow{2}{*}{$\frac{N}{2,416}$} & \multicolumn{2}{|c|}{ Ki67-LI (Mean \pm SEM) } & \multirow[t]{2}{*}{$P$} \\
\hline & & & 2.0 & 0.05 & \\
\hline \multirow[t]{3}{*}{ All } & Cytoplasmic only & 1,741 & 3.1 & 0.06 & $<0.0001$ \\
\hline & Nuclear accumulation & 1,467 & 3.6 & 0.07 & \\
\hline & Negative & 678 & 1.8 & 0.08 & \\
\hline \multirow[t]{3}{*}{$\leq 3+3$} & Cytoplasmic only & 341 & 2.6 & 0.11 & $<0.0001$ \\
\hline & Nuclear accumulation & 175 & 3.0 & 0.15 & \\
\hline & Negative & 1,297 & 2.0 & 0.06 & \\
\hline \multirow[t]{3}{*}{$3+4$} & Cytoplasmic only & 1,039 & 3.0 & 0.07 & $<0.0001$ \\
\hline & Nuclear accumulation & 795 & 3.2 & 0.08 & \\
\hline & Negative & 94 & 2.3 & 0.24 & \\
\hline \multirow[t]{3}{*}{$3+4$ Tertiary 5} & Cytoplasmic only & 61 & 3.5 & 0.30 & $<0.0001$ \\
\hline & Nuclear accumulation & 73 & 3.5 & 0.27 & \\
\hline & Negative & 169 & 2.1 & 0.23 & \\
\hline \multirow[t]{3}{*}{$4+3$} & Cytoplasmic only & 183 & 3.5 & 0.22 & $<0.0001$ \\
\hline & Nuclear accumulation & 185 & 4.2 & 0.22 & \\
\hline & Negative & 91 & 2.2 & 0.39 & \\
\hline \multirow[t]{3}{*}{$4+3$ Tertiary 5} & Cytoplasmic only & 63 & 3.9 & 0.47 & $<0.0001$ \\
\hline & Nuclear accumulation & 127 & 4.7 & 0.33 & \\
\hline & Negative & 86 & 3.5 & 0.52 & \\
\hline \multirow[t]{2}{*}{$\geq 4+4$} & Cytoplasmic only & 53 & 4.8 & 0.67 & 0.0101 \\
\hline & Nuclear accumulation & 109 & 5.5 & 0.47 & \\
\hline
\end{tabular}

SEM, standard error of the mean.

demonstrate that such deletions are more prevalent than mutations of coding genes and many of these deletions have been linked to either ERG positive (i.e. PTEN and 3 p13) or ERG negative cancers (i.e. $6 q 15$ and $5 q 23$ ) [48-52]. Finding a link between all of these deletions and GSK3ß up-regulation - exclusively in the subset of ERG negative cancers - suggests that GSK3ß might contribute to genomic instability at least in the absence of ERG. Several specific functions of GSK3ß and clinical observations are compatible with this assumption. GSK3ß is critically involved in microtubule remodeling [53], and it was shown to localize to the spindle pole in mitosis [54]. That many GSK3-inhibitors have been shown to cause chromosome misalignment and misssegregation [55] strongly supports a functional link between disturbed GSK3ß homeostasis, failure of the spindle apparatus, and loss of genome integrity. We can only speculate why relevant associations between GSK 33 and genomic deletions were absented in ERG fusion positive cancers. However, it cannot be excluded that one or more target genes of ERG interfere with mechanisms linking GSK3ß to microtubule functionality. One example is the microtubule-associated protein Tau [56]. We have earlier shown that critical components of microtubules or their turnover, such as BIII-tubulin [57] or Tau protein
(Schroeder et al., submitted), are strongly up-regulated in ERG positive as compared to ERG negative cancers.

That GSK3ß analysis provided additional prognostic information beyond the established preoperative and postoperative prognostic parameters in prostate cancer makes it a promising candidate for potential routine diagnostic applications. Remarkably, the analysis of the prognostic role of nuclear GSK3ß up-regulation in subgroups of prostate cancers that were narrowly defined by identical classical and quantitative Gleason grades suggest a limitation of the prognostic value of GSK3ß measurement to cancers with Gleason grade $3+4$ and $4+3$. This limitation of the prognostic impact to these subgroups is not disappointing as these tumors are subject to the most difficult therapeutic decision making with options ranging from active surveillance to prostatectomy. The Gleason grading system is purely based on the simple distinction of architectural features, neglects any cytological criteria, but is statistically extremely powerful. The prognostic power of the Gleason grade is much higher than the histologic grading in various other cancer types, such as for example kidney cancer [58] or invasive bladder cancer [59]. This holds true if the Gleason grading method is limited to 5 prognostic subgroups [60]. Based on the analysis of a cohort of more than 10,000 prostate cancers available at 
our institution, we had earlier shown that Gleason Grade information can be refined by using the percentage of Gleason 4 grades as a continuous variable. Both in biopsies and in prostatectomy samples, prostate cancer prognosis deteriorates gradually with increasing percentage of Gleason 4 pattern (quantitative Gleason Grade) [61]. That nuclear accumulation of GSK3ß is even prognostically relevant in some prostate cancer subgroups defined by a comparable Gleason 4 fraction provides further arguments for a possible clinical application of GSK3ß analysis for assessing prostate cancer aggressiveness.

The therapeutic potential of GSK $3 ß$ inhibition has become an important area of investigation. More than 50 compounds targeting GSK $3 \beta$ have been described as to yet [4]. Evidence for a possible therapeutic application of some of these drugs in cancer comes from in-vitro and in-vivo xenograft models. For example, GSK3ß inhibition reduces cell proliferation, increases apoptosis, and sensitizes to gemcitabine in pancreatic cancer cells [62], reduces viability of ovarian cancer cells [8], increases apoptosis in colon cancer cells [63], and reduces cell proliferation and survival in lung cancer cells [11]. Clinical phase I/II trials have been completed in patients with acute leukemia (NCT01214603) and advanced or metastatic solid cancers (NCT01287520) using the GSK3ß inhibitor LY2090314, and another phase II study on metastatic pancreatic cancer (NCT01632306) is currently recruiting participants. Should these studies provide evidence for a

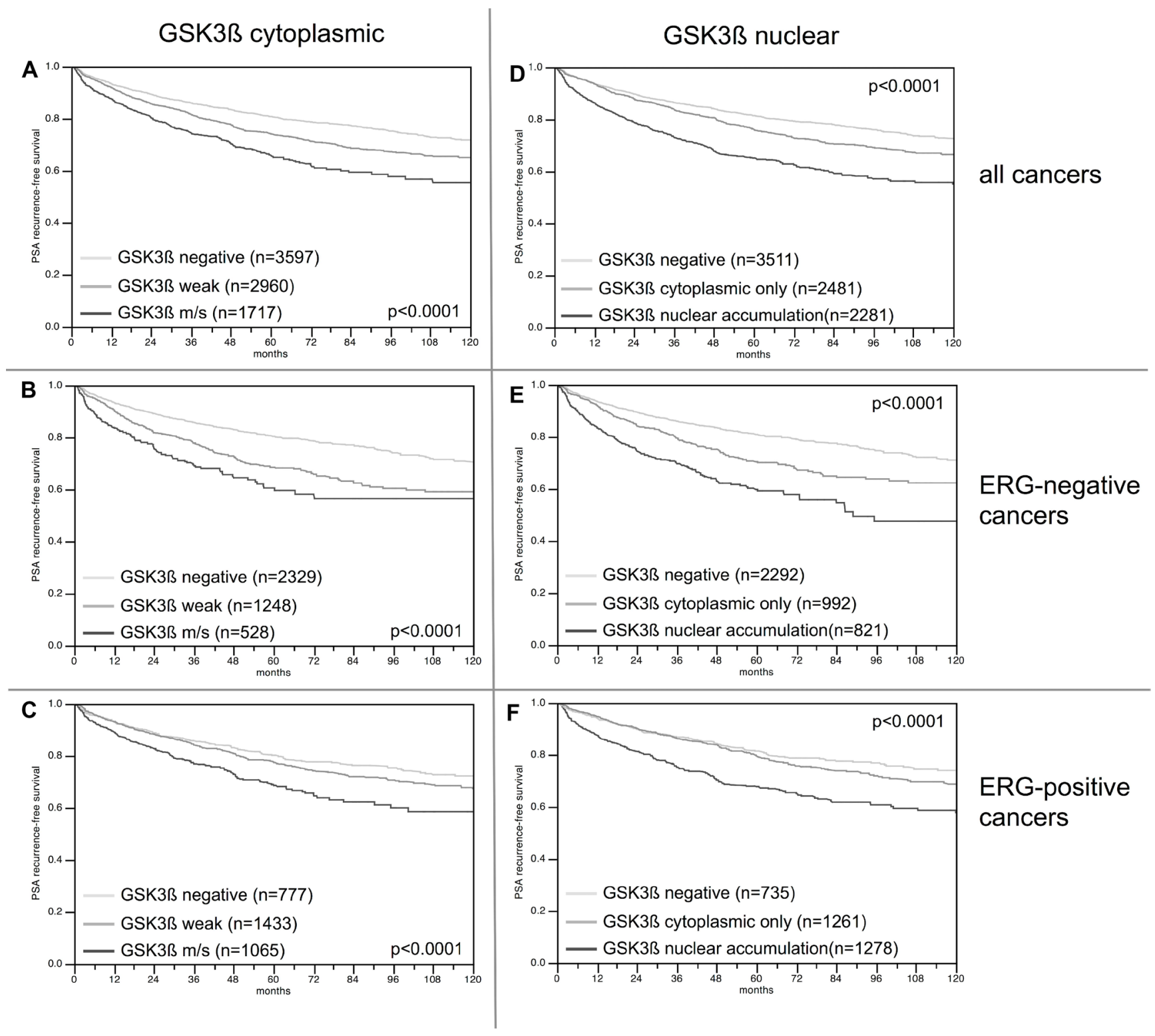

Figure 6: Kaplan-Meier analysis of PSA recurrence-free survival after radical prostatectomy and (A-C) cytoplasmic GSK3ß expression, and (D-F) nuclear GSK3ß accumulation in all cancers and the ERG negative and positive subset; $\mathrm{m} / \mathrm{s}$ : moderate or strong cytoplasmic GSK3ß staining. 

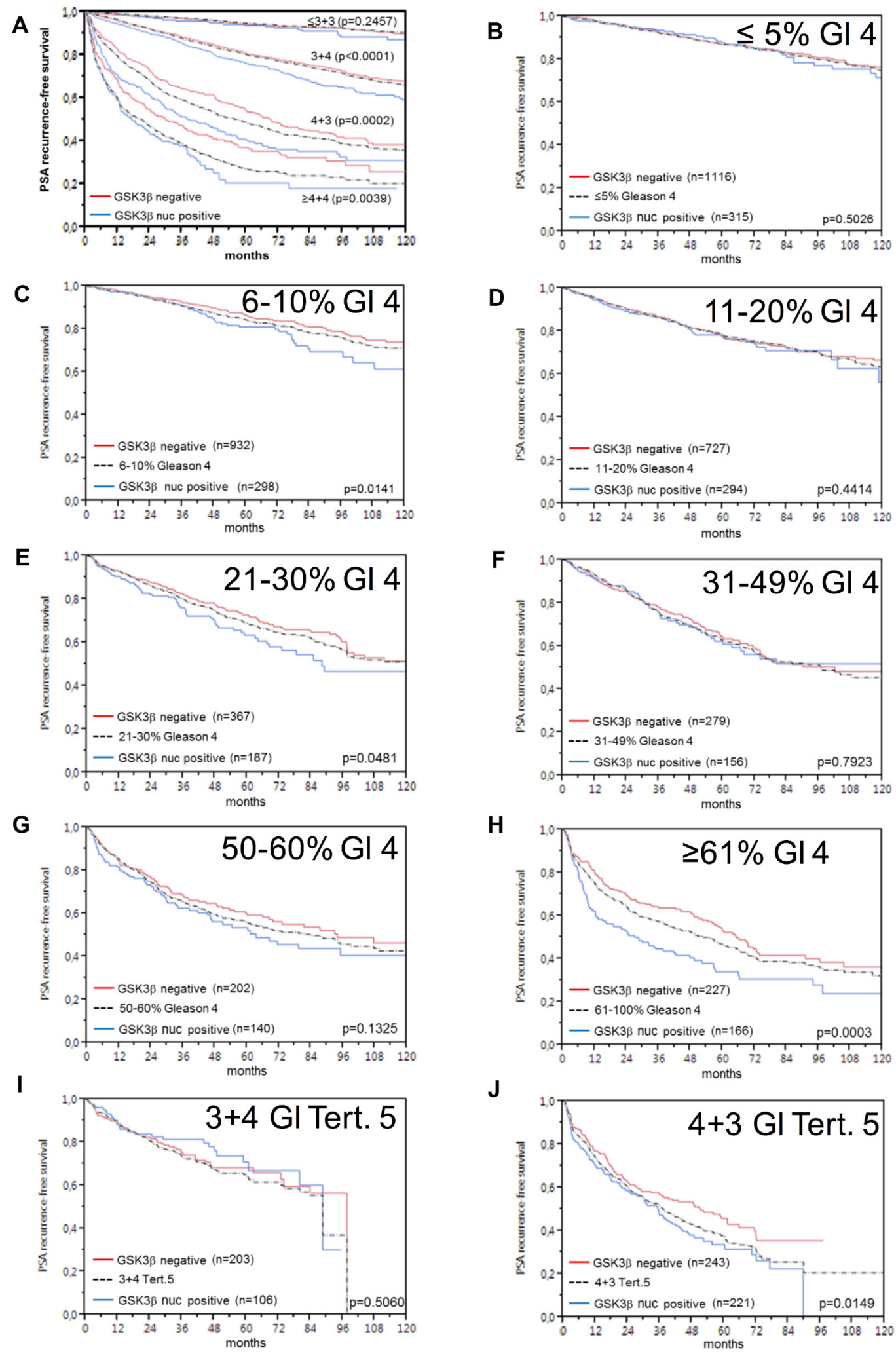

Figure 7: Prognostic impact of GSK3ß expression in subsets of cancers defined by the Gleason score. (A) Impact of negative (red line) and nuclear positive (blue line) GSK3 $\beta$ expression as compared to the classical Gleason score categories (indicated by black dotted lines). (B-H) Impact of negative (red line) and nuclear positive (blue line) GSK3 $\beta$ expression in the quantitative Gleason score categories (black dotted lines) defined by the percentage of (B) $\leq 5 \%,(\mathbf{C}) 6-10 \%$, (D) $11-20 \%$, (E) 21-30\%, (F) 31-49 \%, (G) 50-60\%, (H) $\geq 61 \%$ Gleason 4 patterns. (I- $-\mathbf{J})$ Impact of Gleason score categories (I) $3+4$ and (J) $4+3$ with tertiary (tert.) Gleason 5 patterns. 
Table 3: Multivariate analysis with established prognostic parameters and the GSK3ß localization in all cancers, the ERG negative and positive subset

\begin{tabular}{|c|c|c|c|c|c|c|c|c|c|c|}
\hline \multirow[b]{2}{*}{ Subset } & \multirow[b]{2}{*}{ Scenario } & \multirow[b]{2}{*}{$N$} & \multicolumn{8}{|c|}{$P$} \\
\hline & & & $\begin{array}{c}\text { Preoperative } \\
\text { PSA-Level }\end{array}$ & $\begin{array}{c}\text { pT } \\
\text { stage }\end{array}$ & $\begin{array}{c}\text { cT } \\
\text { stage }\end{array}$ & $\begin{array}{c}\text { Gleason } \\
\text { grade } \\
\text { prostatectomy }\end{array}$ & $\begin{array}{c}\text { Gleason } \\
\text { grade biopsy }\end{array}$ & $\begin{array}{c}\mathrm{pN} \\
\text { stage }\end{array}$ & $\begin{array}{c}\text { R } \\
\text { status }\end{array}$ & $\begin{array}{c}\text { GSK3ß- } \\
\text { localisation }\end{array}$ \\
\hline \multirow[t]{4}{*}{$\begin{array}{l}\text { All } \\
\text { cancers }\end{array}$} & 1 & 5,057 & $<0.0001$ & $<0.0001$ & - & $<0.0001$ & - & $<0.0001$ & 0.0026 & $<0.0001$ \\
\hline & 2 & 8,086 & $<0.0001$ & $<0.0001$ & - & $<0.0001$ & - & - & $<0.0001$ & $<0.0001$ \\
\hline & 3 & 7,987 & $<0.0001$ & - & $<0.0001$ & $<0.0001$ & - & - & - & $<0.0001$ \\
\hline & 4 & 7,884 & $<0.0001$ & - & $<0.0001$ & - & $<0.0001$ & - & - & $<0.0001$ \\
\hline \multirow[t]{4}{*}{$\begin{array}{l}\text { ERG- } \\
\text { negative }\end{array}$} & 1 & 2,575 & 0.0003 & $<0.0001$ & - & $<0.0001$ & - & 0.0131 & 0.1651 & $<0.0001$ \\
\hline & 2 & 4,020 & $<0.0001$ & $<0.0001$ & - & $<0.0001$ & - & - & 0.0005 & $<0.0001$ \\
\hline & 3 & 3,988 & $<0.0001$ & - & $<0.0001$ & $<0.0001$ & - & - & - & $<0.0001$ \\
\hline & 4 & 3,934 & $<0.0001$ & - & $<0.0001$ & - & $<0.0001$ & - & - & $<0.0001$ \\
\hline \multirow[t]{4}{*}{$\begin{array}{l}\text { ERG- } \\
\text { positive }\end{array}$} & 1 & 2,037 & 0.0001 & $<0.0001$ & - & $<0.0001$ & - & 0.0164 & 0.0075 & $<0.0001$ \\
\hline & 2 & 3,199 & $<0.0001$ & $<0.0001$ & - & $<0.0001$ & - & - & $<0.0001$ & 0.0001 \\
\hline & 3 & 3,138 & $<0.0001$ & - & $<0.0001$ & $<0.0001$ & - & - & - & 0.0002 \\
\hline & 4 & 3,099 & $<0.0001$ & - & $<0.0001$ & - & $<0.0001$ & - & - & $<0.0001$ \\
\hline
\end{tabular}

Scenario 1 includes all postoperatively available parameters (pathological tumor (pT) stage, lymph node status (pN), surgical margin (R) status, preoperative PSA value and Gleason grade obtained after the morphological evaluation of the entire resected prostate. Scenario 2 excluded the nodal status from analysis. Scenario 3 included preoperative PSA, clinical tumor (cT) stage and Gleason grade obtained on the prostatectomy specimen. In scenario 4, the preoperative Gleason grade obtained on the original biopsy was combined with preoperative PSA, and cT stage.

clinical benefit of GSK3ß inhibition in cancer therapy, the results of our study would justify evaluating prostate cancer in future GSK3ß inhibition trials.

In summary, the results of our study identify nuclear GSK3ß accumulation as a moderate and independent prognosticator in prostate cancer. GSK3ß expression analysis has the potential for a clinical routine application - either alone, or more likely, in combination with other biomarkers.

\section{MATERIALS AND METHODS}

\section{Patients}

Radical prostatectomy specimens were used from 12,427 patients, who had surgery between 1992 and 2012 (Department of Urology and the Martini Clinic at the University Medical Center Hamburg-Eppendorf). Specimens were analyzed by a standard procedure with embedding of the entire prostate for histological analysis [25]. In addition to the classical Gleason categories, "quantitative" Gleason grading was performed as described before [61]. Median follow-up was 48.9 months (range: 1 to 275 months; Table 4). PSA recurrence was defined as the time point when the postoperative PSA level was at least $0.2 \mathrm{ng} / \mathrm{ml}$ and increasing at subsequent measurements. Tissue microarrays (TMA) were produced as described earlier in detail [64]. Each TMA block contained various control tissues and normal prostate. The TMA was annotated with results on ERG expression, ERG break apart FISH analysis [65] and deletion status of 5q21 (CHD1) [48], 6q15 (MAP3K7) [48], PTEN (10q23) [49], 3p13 (FOXP1) [50], KI67 labeling Index (Ki67LI) [66] and androgen receptor (AR) expression [23]. The usage of archived diagnostic leftover tissues for TMAs and their analysis for research purposes has been approved by local laws (HmbKHG, §12a) and by the Ärztekammer Hamburg (WF-049/09). The work has been carried out in compliance with the Helsinki Declaration.

\section{Immunohistochemistry (IHC)}

Freshly cut TMA sections were immunostained on the same day and in one experiment. Slides were 


\begin{tabular}{|c|c|c|}
\hline & \multicolumn{2}{|c|}{ No. of patients } \\
\hline & Study cohort on tissue microarray & Biochemical relapse among categories \\
\hline \multicolumn{3}{|l|}{ Follow-up } \\
\hline$n$ & 11665 & $2769(23.7 \%)$ \\
\hline Mean/Median (month) & $56.3 / 48.9$ & \\
\hline \multicolumn{3}{|l|}{ Age (y) } \\
\hline$\leq 50$ & 334 & $81(24.3 \%)$ \\
\hline $51-59$ & 3061 & $705(23 \%)$ \\
\hline $60-69$ & 7188 & $1610(22.4 \%)$ \\
\hline$\geq 70$ & 1761 & $370(21 \%)$ \\
\hline \multicolumn{3}{|c|}{ Pretreatment PSA (ng/ml) } \\
\hline$<4$ & 1585 & $242(15.3 \%)$ \\
\hline $4-10$ & 7480 & $1355(18.1 \%)$ \\
\hline $10-20$ & 2412 & $737(30.6 \%)$ \\
\hline$>20$ & 812 & $397(48.9 \%)$ \\
\hline \multicolumn{3}{|l|}{ pT stage (AJCC 2002) } \\
\hline pT2 & 8187 & $1095(13.4 \%)$ \\
\hline pT3a & 2,660 & $817(30.7 \%)$ \\
\hline $\mathrm{pT} 3 \mathrm{~b}$ & 1465 & $796(54.3 \%)$ \\
\hline pT4 & 63 & $51(81 \%)$ \\
\hline \multicolumn{3}{|l|}{ Gleason grade } \\
\hline$\leq 3+3$ & 2848 & $234(8.2 \%)$ \\
\hline $3+4$ & 6679 & $1240(18.6 \%)$ \\
\hline $3+4$ Tertiary 5 & 433 & $115(26.6 \%)$ \\
\hline $4+3$ & 1210 & $576(47.6 \%)$ \\
\hline $4+3$ Tertiary 5 & 646 & $317(49.1 \%)$ \\
\hline$\geq 4+4$ & 596 & $348(58.4 \%)$ \\
\hline \multicolumn{3}{|l|}{ pN stage } \\
\hline pN0 & 6970 & $1636(23.5 \%)$ \\
\hline $\mathrm{pN}+$ & 693 & $393(56.7 \%)$ \\
\hline \multicolumn{3}{|l|}{ Surgical margin } \\
\hline Negative & 9990 & $1848(18.5 \%)$ \\
\hline Positive & 2211 & $853(38.6 \%)$ \\
\hline
\end{tabular}

In the column "Study cohort on tissue microarray" numbers do not always add up to 12427 in different categories because of cases with missing data. Percent in column "Biochemical relapse among categories" refers to the fraction of samples with biochemical relapse within each parameter in the different categories. Abbreviation: AJCC, American Joint Committee on Cancer.

deparaffinized and exposed to antigen retrieval for 5 minutes at $121^{\circ} \mathrm{C}$ in $\mathrm{pH} 7.8$ Tris-EDTA buffer. Primary antibody specific for total GSK3B (rabbit monoclonal antibody, Cell Signaling Technology, USA; cat\#12456; dilution 1:900) was applied at $37^{\circ} \mathrm{C}$ for 60 minutes. Bound antibody was then visualized using the EnVision Kit (Dako, Glostrup, Denmark) according to the manufacturer's directions. GSK3ß staining of variable intensity was seen in the cytoplasm, which was often accompanied by nuclear co-staining of similar intensity. Since GSK3ß positive cancers typically showed staining of all $(100 \%)$ tumor cells, we recorded the cytoplasmic staining intensity (0 (negative), 1+(weak), 2+ (moderate), and $3+$ (strong) as well as the presence or absence of nuclear co-staining for each tissue spot, but not the percentage of stained tumor cells. 


\section{Statistics}

Statistical calculations were done with JMP ${ }^{\circledR} 10$ (SAS Institute Inc., NC, USA). Contingency tables and chi $^{2}$-test were performed to look for associations between molecular parameters and tumor phenotype. KaplanMeier survival curves were calculated and tested with the log-rank test for significant differences between groups. Cox proportional hazards regression analysis tested the statistical independence and significance between pathological, molecular and clinical variables in various clinical models.

\section{ACKNOWLEDGMENTS}

We are grateful to Christina Koop, Janett Lütgens, Sünje Seekamp, and Inge Brandt for excellent technical assistance.

\section{CONFLICTS OF INTEREST}

The authors declare no financial conflicts of interest.

\section{FUNDING}

Not applicable.

\section{REFERENCES}

1. Bray F, Ferlay J, Soerjomataram I, Siegel RL, Torre LA, Jemal A. Global cancer statistics 2018: GLOBOCAN estimates of incidence and mortality worldwide for 36 cancers in 185 countries. CA Cancer J Clin. 2018; 68:394-424.

2. Wilt TJ, Brawer MK, Jones KM, Barry MJ, Aronson WJ, Fox S, Gingrich JR, Wei JT, Gilhooly P, Grob BM, Nsouli I, Iyer P, Cartagena R, et al. Radical prostatectomy versus observation for localized prostate cancer. N Engl J Med. 2012; 367:203-13.

3. Thompson IM Jr, Tangen CM. Prostate cancer--uncertainty and a way forward. N Engl J Med. 2012; 367:270-1.

4. McCubrey JA, Steelman LS, Bertrand FE, Davis NM, Sokolosky M, Abrams SL, Montalto G, D'Assoro AB, Libra M, Nicoletti F, Maestro R, Basecke J, Rakus D, et al. GSK-3 as potential target for therapeutic intervention in cancer. Oncotarget. 2014; 5:2881-911. https:/doi. org/10.18632/oncotarget.2037.

5. Bechard M, Trost R, Singh AM, Dalton S. Frat is a phosphatidylinositol 3-kinase/Akt-regulated determinant of glycogen synthase kinase 3beta subcellular localization in pluripotent cells. Mol Cell Biol. 2012; 32:288-96.

6. Quintayo MA, Munro AF, Thomas J, Kunkler IH, Jack W, Kerr GR, Dixon JM, Chetty U, Bartlett JM. GSK3beta and cyclin D1 expression predicts outcome in early breast cancer patients. Breast Cancer Res Treat. 2012; 136:161-8.

7. Mylona E, Vamvakaris I, Giannopoulou I, Theohari I, Papadimitriou C, Keramopoulos A, Nakopoulou L. An immunohistochemical evaluation of the proteins Wnt 1 and glycogen synthase kinase (GSK)-3beta in invasive breast carcinomas. Histopathology. 2013; 62:899-907.

8. Fu Y, Wang X, Cheng X, Ye F, Xie X, Lu W. Clinicopathological and biological significance of aberrant activation of glycogen synthase kinase-3 in ovarian cancer. Onco Targets Ther. 2014; 7:1159-68.

9. Mishra R, Nagini S, Rana A. Expression and inactivation of glycogen synthase kinase $3 \mathrm{alpha} /$ beta and their association with the expression of cyclin D1 and p53 in oral squamous cell carcinoma progression. Mol Cancer. 2015; 14:20.

10. Naito S, Bilim V, Yuuki K, Ugolkov A, Motoyama T, Nagaoka A, Kato T, Tomita Y. Glycogen synthase kinase3beta: a prognostic marker and a potential therapeutic target in human bladder cancer. Clin Cancer Res. 2010; 16:5124-32.

11. Zeng J, Liu D, Qiu Z, Huang Y, Chen B, Wang L, Xu H, Huang N, Liu L, Li W. GSK3beta overexpression indicates poor prognosis and its inhibition reduces cell proliferation and survival of non-small cell lung cancer cells. PLoS One. 2014; 9:e91231

12. Zheng HC, Xu XY, Xia P, Yu M, Takahashi H, Takano $\mathrm{Y}$. Involvement of inactive GSK3beta overexpression in tumorigenesis and progression of gastric carcinomas. Hum Pathol. 2010; 41:1255-64.

13. Ougolkov AV, Fernandez-Zapico ME, Bilim VN, Smyrk TC, Chari ST, Billadeau DD. Aberrant nuclear accumulation of glycogen synthase kinase-3beta in human pancreatic cancer: association with kinase activity and tumor dedifferentiation. Clin Cancer Res. 2006; 12:5074-81.

14. Walz A, Ugolkov A, Chandra S, Kozikowski A, Carneiro BA, O'Halloran TV, Giles FJ, Billadeau DD, Mazar AP. Molecular Pathways: Revisiting Glycogen Synthase Kinase- $3 \beta$ as a Target for the Treatment of Cancer. Clin Cancer Res. 2017; 23:1891-1897.

15. Li R, Erdamar S, Dai H, Sayeeduddin M, Frolov A, Wheeler TM, Ayala GE. Cytoplasmic accumulation of glycogen synthase kinase-3beta is associated with aggressive clinicopathological features in human prostate cancer. Anticancer Res. 2009; 29:2077-81.

16. Millet JP, Orcau A, Rius C, Casals M, de Olalla PG, Moreno A, Nelson JL, Cayla JA, Barcelona Tuberculosis Working G. Predictors of death among patients who completed tuberculosis treatment: a population-based cohort study. PLoS One. 2011; 6:e25315.

17. Schutz SV, Cronauer MV, Rinnab L. Inhibition of glycogen synthase kinase-3beta promotes nuclear export of the androgen receptor through a CRM1-dependent mechanism in prostate cancer cell lines. J Cell Biochem. 2010; 109:1192-200. 
18. Liao X, Thrasher JB, Holzbeierlein J, Stanley S, Li B. Glycogen synthase kinase-3beta activity is required for androgen-stimulated gene expression in prostate cancer. Endocrinology. 2004; 145:2941-9.

19. Mulholland DJ, Dedhar S, Wu H, Nelson CC. PTEN and GSK3beta: key regulators of progression to androgenindependent prostate cancer. Oncogene. 2006; 25:329-37.

20. Campa VM, Baltziskueta E, Bengoa-Vergniory N, GorronoEtxebarria I, Wesolowski R, Waxman J, Kypta RM. A screen for transcription factor targets of glycogen synthase kinase-3 highlights an inverse correlation of $\mathrm{NF \kappa B}$ and androgen receptor signaling in prostate cancer. Oncotarget. 2014; 5:8173-87. https://doi.org/10.18632/oncotarget.2303.

21. Wang L, Lin HK, Hu YC, Xie S, Yang L, Chang C. Suppression of androgen receptor-mediated transactivation and cell growth by the glycogen synthase kinase 3 beta in prostate cells. J Biol Chem. 2004; 279:32444-52.

22. Darrington RS, Campa VM, Walker MM, BengoaVergniory N, Gorrono-Etxebarria I, Uysal-Onganer P, Kawano Y, Waxman J, Kypta RM. Distinct expression and activity of GSK-3alpha and GSK-3beta in prostate cancer. Int J Cancer. 2012; 131:E872-83.

23. Weischenfeldt J, Simon R, Feuerbach L, Schlangen K, Weichenhan D, Minner S, Wuttig D, Warnatz HJ, Stehr H, Rausch T, Jager N, Gu L, Bogatyrova O, et al. Integrative genomic analyses reveal an androgen-driven somatic alteration landscape in early-onset prostate cancer. Cancer Cell. 2013; 23:159-70.

24. Epstein JI, Feng Z, Trock BJ, Pierorazio PM. Upgrading and downgrading of prostate cancer from biopsy to radical prostatectomy: incidence and predictive factors using the modified Gleason grading system and factoring in tertiary grades. Eur Urol. 2012; 61:1019-24.

25. Schlomm T, Iwers L, Kirstein P, Jessen B, Kollermann J, Minner S, Passow-Drolet A, Mirlacher M, Milde-Langosch K, Graefen M, Haese A, Steuber T, Simon R, et al. Clinical significance of $\mathrm{p} 53$ alterations in surgically treated prostate cancers. Mod Pathol. 2008; 21:1371-9.

26. Bertheau P, Cazals-Hatem D, Meignin V, de Roquancourt A, Verola O, Lesourd A, Sene C, Brocheriou C, Janin A. Variability of immunohistochemical reactivity on stored paraffin slides. J Clin Pathol. 1998; 51:370-4.

27. Yaziji H, Barry T. Diagnostic immunohistochemistry: what can go wrong? Adv Anat Pathol. 2006; 13:238-46.

28. Kim SW, Roh J, Park CS. Immunohistochemistry for pathologists: Protocols, pitfalls, and tips. J Pathol Transl Med. 2016; 50:411-8.

29. Diehl JA, Cheng M, Roussel MF, Sherr CJ. Glycogen synthase kinase-3beta regulates cyclin D1 proteolysis and subcellular localization. Genes Dev. 1998; 12:3499-511.

30. Ginger RS, Dalton EC, Ryves WJ, Fukuzawa M, Williams JG, Harwood AJ. Glycogen synthase kinase-3 enhances nuclear export of a Dictyostelium STAT protein. EMBO J. 2000; 19:5483-91.
31. Morisco C, Seta K, Hardt SE, Lee Y, Vatner SF, Sadoshima J. Glycogen synthase kinase 3beta regulates GATA4 in cardiac myocytes. J Biol Chem. 2001; 276:28586-97.

32. Gregory MA, Qi Y, Hann SR. Phosphorylation by glycogen synthase kinase-3 controls c-myc proteolysis and subnuclear localization. J Biol Chem. 2003; 278:51606-12.

33. Salazar M, Rojo AI, Velasco D, de Sagarra RM, Cuadrado A. Glycogen synthase kinase-3beta inhibits the xenobiotic and antioxidant cell response by direct phosphorylation and nuclear exclusion of the transcription factor Nrf2. J Biol Chem. 2006; 281:14841-51.

34. Yook JI, Li XY, Ota I, Fearon ER, Weiss SJ. Wnt-dependent regulation of the E-cadherin repressor snail. J Biol Chem. $2005 ; 280: 11740-8$.

35. Watcharasit P, Bijur GN, Zmijewski JW, Song L, Zmijewska A, Chen X, Johnson GV, Jope RS. Direct, activating interaction between glycogen synthase kinase-3beta and p53 after DNA damage. Proc Natl Acad Sci U S A. 2002; 99:7951-5.

36. Brase JC, Johannes M, Mannsperger H, Falth M, Metzger J, Kacprzyk LA, Andrasiuk T, Gade S, Meister M, Sirma H, Sauter G, Simon R, Schlomm T, et al. TMPRSS2-ERG -specific transcriptional modulation is associated with prostate cancer biomarkers and TGF-beta signaling. BMC Cancer. 2011; 11:507.

37. Tomlins SA, Rhodes DR, Perner S, Dhanasekaran SM, Mehra R, Sun XW, Varambally S, Cao X, Tchinda J, Kuefer $\mathrm{R}$, Lee C, Montie JE, Shah RB, et al. Recurrent fusion of TMPRSS2 and ETS transcription factor genes in prostate cancer. Science. 2005; 310:644-8.

38. Wu L, Zhao JC, Kim J, Jin HJ, Wang CY, Yu J. ERG is a critical regulator of Wnt/LEF1 signaling in prostate cancer. Cancer Res. 2013; 73:6068-79.

39. Li Y, Kong D, Wang Z, Ahmad A, Bao B, Padhye S, Sarkar FH. Inactivation of AR/TMPRSS2-ERG/Wnt signaling networks attenuates the aggressive behavior of prostate cancer cells. Cancer Prev Res (Phila). 2011; 4:1495-506.

40. Shang $\mathrm{S}, \mathrm{Hua} F, \mathrm{Hu} \mathrm{ZW}$. The regulation of $\beta$-catenin activity and function in cancer: therapeutic opportunities. Oncotarget. 2017; 8:33972-89. https://doi.org/10.18632/ oncotarget.15687.

41. Giles RH, van Es JH, Clevers H. Caught up in a Wnt storm: Wnt signaling in cancer. Biochim Biophys Acta. 2003; 1653:1-24.

42. Kikuchi A, Kishida S, Yamamoto H. Regulation of Wnt signaling by protein-protein interaction and posttranslational modifications. Exp Mol Med. 2006; 38:1-10.

43. Caspi M, Zilberberg A, Eldar-Finkelman H, RosinArbesfeld R. Nuclear GSK-3beta inhibits the canonical Wnt signalling pathway in a beta-catenin phosphorylationindependent manner. Oncogene. 2008; 27:3546-55.

44. Shin SH, Lee EJ, Chun J, Hyun S, Kim YI, Kang SS. The nuclear localization of glycogen synthase kinase 3 beta is 
required its putative PY-nuclear localization sequences. Mol Cells. 2012; 34:375-82.

45. Patel S, Doble B, Woodgett JR. Glycogen synthase kinase-3 in insulin and Wnt signalling: a double-edged sword? Biochem Soc Trans. 2004; 32:803-8.

46. Mazor M, Kawano Y, Zhu H, Waxman J, Kypta RM. Inhibition of glycogen synthase kinase-3 represses androgen receptor activity and prostate cancer cell growth. Oncogene. 2004; 23:7882-92.

47. Rinnab L, Schutz SV, Diesch J, Schmid E, Kufer R, Hautmann RE, Spindler KD, Cronauer MV. Inhibition of glycogen synthase kinase-3 in androgen-responsive prostate cancer cell lines: are GSK inhibitors therapeutically useful? Neoplasia. 2008; 10:624-34.

48. Burkhardt L, Fuchs S, Krohn A, Masser S, Mader M, Kluth M, Bachmann F, Huland H, Steuber T, Graefen M, Schlomm T, Minner S, Sauter G, et al. CHD1 is a $5 \mathrm{q} 21$ tumor suppressor required for ERG rearrangement in prostate cancer. Cancer Res. 2013; 73:2795-805.

49. Krohn A, Diedler T, Burkhardt L, Mayer PS, De Silva C, Meyer-Kornblum M, Kotschau D, Tennstedt P, Huang J, Gerhauser C, Mader M, Kurtz S, Sirma H, et al. Genomic deletion of PTEN is associated with tumor progression and early PSA recurrence in ERG fusion-positive and fusionnegative prostate cancer. Am J Pathol. 2012; 181:401-12.

50. Krohn A, Seidel A, Burkhardt L, Bachmann F, Mader M, Grupp K, Eichenauer T, Becker A, Adam M, Graefen M, Huland H, Kurtz S, Steurer S, et al. Recurrent deletion of 3 p13 targets multiple tumour suppressor genes and defines a distinct subgroup of aggressive ERG fusion-positive prostate cancers. J Pathol. 2013; 231:130-41.

51. Taylor BS, Schultz N, Hieronymus H, Gopalan A, Xiao Y, Carver BS, Arora VK, Kaushik P, Cerami E, Reva B, Antipin Y, Mitsiades N, Landers T, et al. Integrative genomic profiling of human prostate cancer. Cancer Cell. 2010; 18:11-22.

52. Lapointe J, Li C, Giacomini CP, Salari K, Huang S, Wang P, Ferrari M, Hernandez-Boussard T, Brooks JD, Pollack JR. Genomic profiling reveals alternative genetic pathways of prostate tumorigenesis. Cancer Res. 2007; 67:8504-10.

53. Xu W, Ge Y, Liu Z, Gong R. Glycogen synthase kinase 3beta orchestrates microtubule remodeling in compensatory glomerular adaptation to podocyte depletion. J Biol Chem. 2015; 290:1348-63.

54. Wakefield JG, Stephens DJ, Tavare JM. A role for glycogen synthase kinase-3 in mitotic spindle dynamics and chromosome alignment. J Cell Sci. 2003; 116:637-46.

55. Tighe A, Ray-Sinha A, Staples OD, Taylor SS. GSK-3 inhibitors induce chromosome instability. BMC Cell Biol. 2007; 8:34.
56. Hooper C, Killick R, Lovestone S. The GSK3 hypothesis of Alzheimer's disease. J Neurochem. 2008; 104:1433-9.

57. Grupp K, Wilking J, Prien K, Hube-Magg C, Sirma H, Simon R, Steurer S, Budaus L, Haese A, Izbicki J, Sauter G, Minner S, Schlomm T, et al. High RNA-binding motif protein 3 expression is an independent prognostic marker in operated prostate cancer and tightly linked to ERG activation and PTEN deletions. Eur J Cancer. 2014; 50:852-61.

58. Ficarra V, Martignoni G, Maffei N, Brunelli M, Novara G, Zanolla L, Pea M, Artibani W. Original and reviewed nuclear grading according to the Fuhrman system: a multivariate analysis of 388 patients with conventional renal cell carcinoma. Cancer. 2005; 103:68-75.

59. Grignon DJ. The current classification of urothelial neoplasms. Mod Pathol. 2009; 22:S60-9.

60. Pierorazio PM, Walsh PC, Partin AW, Epstein JI. Prognostic Gleason grade grouping: data based on the modified Gleason scoring system. BJU Int. 2013; 111:753-60.

61. Sauter G, Steurer S, Clauditz TS, Krech T, Wittmer C, Lutz F, Lennartz M, Janssen T, Hakimi N, Simon R, von Petersdorff-Campen M, Jacobsen F, von Loga K, et al. Clinical utility of quantitative gleason grading in prostate biopsies and prostatectomy specimens. Eur Urol. 2016; 69:592-8.

62. Zhang Q, Bhojani MS, Ben-Josef E, Spalding AC, Kuick R, Sun Y, Morgan MA. Glycogen Synthase Kinase 3beta in pancreatic cancer and its implications in chemotherapy and radiation therapy. J Carcinog Mutagen. 2013; 4:147.

63. Li H, Huang K, Liu X, Liu J, Lu X, Tao K, Wang G, Wang J. Lithium chloride suppresses colorectal cancer cell survival and proliferation through ROS/GSK-3beta/ NF-kappaB signaling pathway. Oxid Med Cell Longev. 2014; 2014:241864.

64. Kononen J, Bubendorf L, Kallioniemi A, Barlund M, Schraml P, Leighton S, Torhorst J, Mihatsch MJ, Sauter G, Kallioniemi OP. Tissue microarrays for high-throughput molecular profiling of tumor specimens. Nat Med. 1998; 4:844-7.

65. Minner S, Enodien M, Sirma H, Luebke AM, Krohn A, Mayer PS, Simon R, Tennstedt P, Muller J, Scholz L, Brase JC, Liu AY, Schluter H, et al. ERG status is unrelated to psa recurrence in radically operated prostate cancer in the absence of antihormonal therapy. Clin Cancer Res. 2011; 17:5878-88.

66. Minner S, Jessen B, Stiedenroth L, Burandt E, Kollermann J, Mirlacher M, Erbersdobler A, Eichelberg C, Fisch M, Brummendorf TH, Bokemeyer C, Simon R, Steuber T, et al. Low level HER2 overexpression is associated with rapid tumor cell proliferation and poor prognosis in prostate cancer. Clin Cancer Res. 2010; 16:1553-60. 